Supporting Information

for:

\title{
Isomorphous Lanthanide Metal-Organic Frameworks based on Biphenyldicarboxylate: Synthesis, Structure and Photoluminescent Properties
}

Ana R. K. Chatenever, ${ }^{+}$Louis R. Warne, ${ }^{+}$Joe E. Matsuoka, ${ }^{+}$Stanley J. Wang, ${ }^{+}$Eric W.

Reinheimer,§ Pierre LeMagueres,, Honghan Fei, ${ }^{\perp}$ Xueling Song $\perp$ and Scott R. J. Oliver $*,+$

+ University of California, Santa Cruz, Department of Chemistry and Biochemistry, 1156 High Street, Santa Cruz, California 95064

$\S$ Rigaku Americas Corporation, 9009 New Trails Drive, The Woodlands, Texas 77381

$\perp$ Tongji University, School of Chemical Science and Engineering, 1239 Siping Road, Shanghai, China 200092 


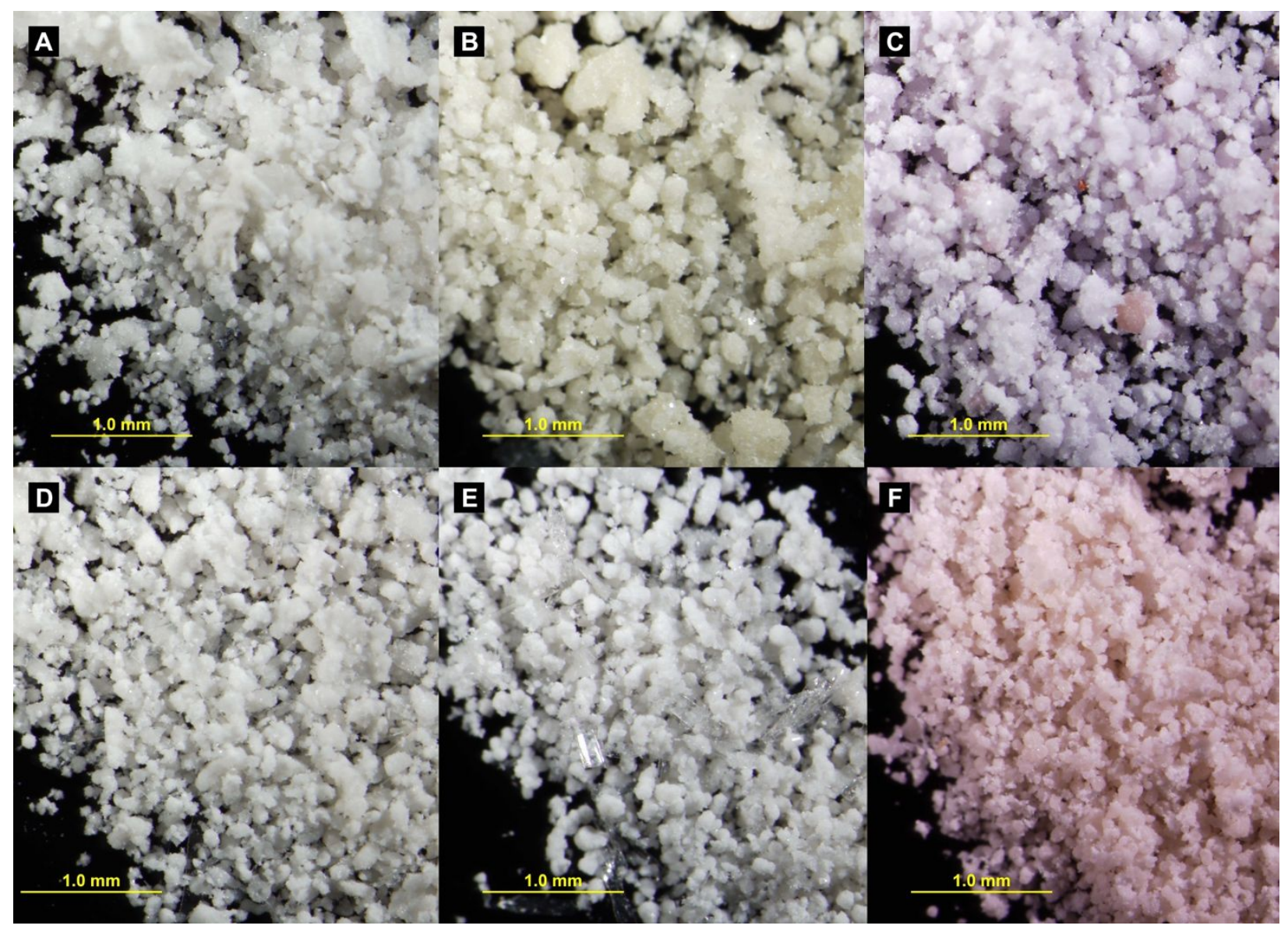

Figure S1. Optical micrographs of the powders of: A) SLUG-43 (La); B) SLUG-44 (Ce); C) SLUG-45 (Nd); D) SLUG-46 (Eu); E) SLUG-47 (Gd); F) SLUG-48 (Er). 

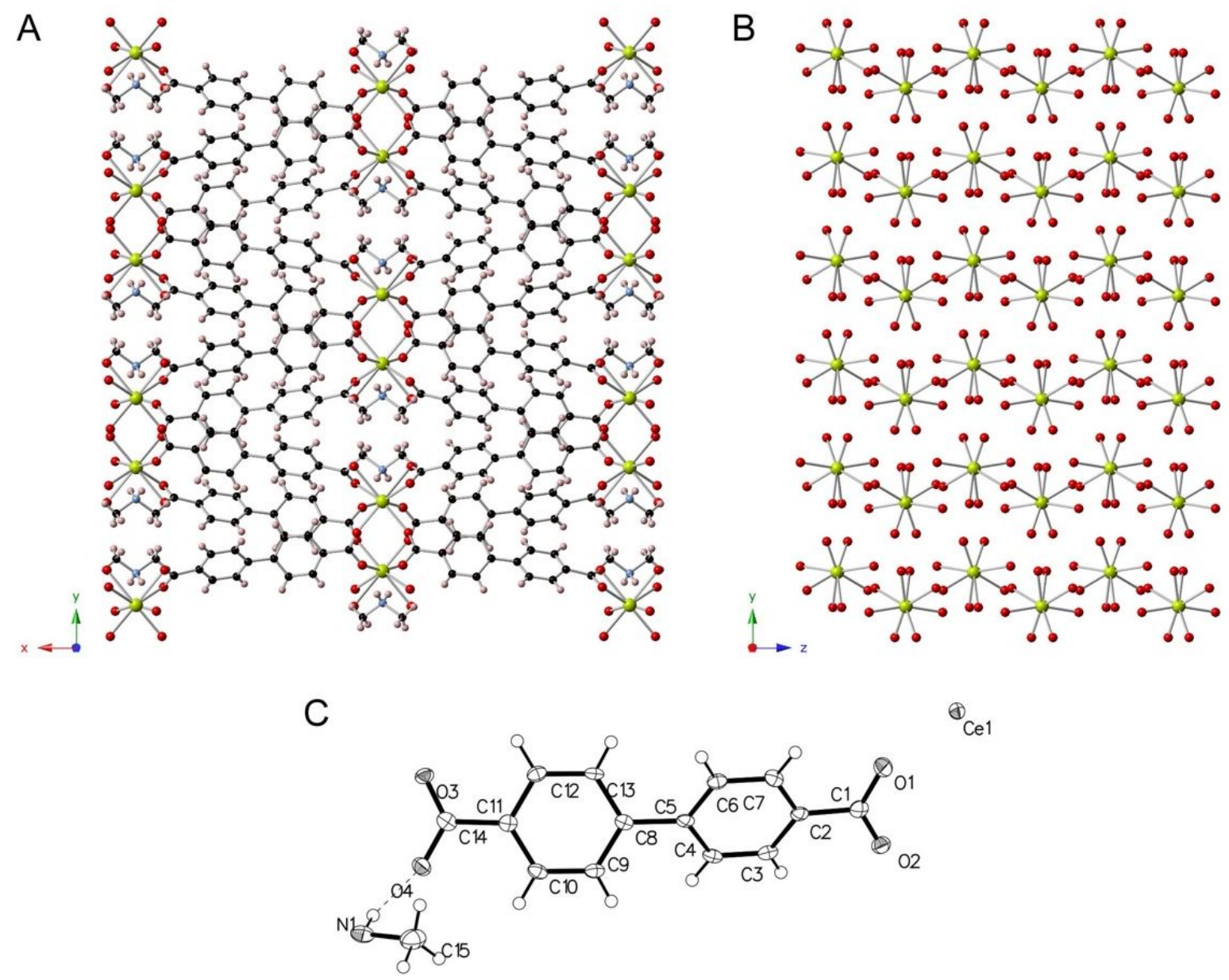

(4)1

Figure S2. Crystallographic projections of SLUG-44 (Ce): A) View along the $c$-axis, showing the metal centers surrounded by $\mathrm{bpdc}^{2-}$ ligands and the extra-framework charge-balancing dimethylammonium ions close to the metal centers ( $\mathrm{Ce}$ - yellow; $\mathrm{O}$ - red; $\mathrm{C}$ - black; $\mathrm{N}$ - light blue; $\mathrm{H}$ - pink); B) View along the $a$-axis of one layer of isolated $\mathrm{CeO}_{8}$ centers $(\mathrm{C}, \mathrm{N}$ and $\mathrm{H}$ omitted for clarity); C) ORTEP (Oak Ridge thermal ellipsoid plot) diagram of SLUG-44 and atomic numbering scheme. Thermal ellipsoids are calculated at $50 \%$ probability. 


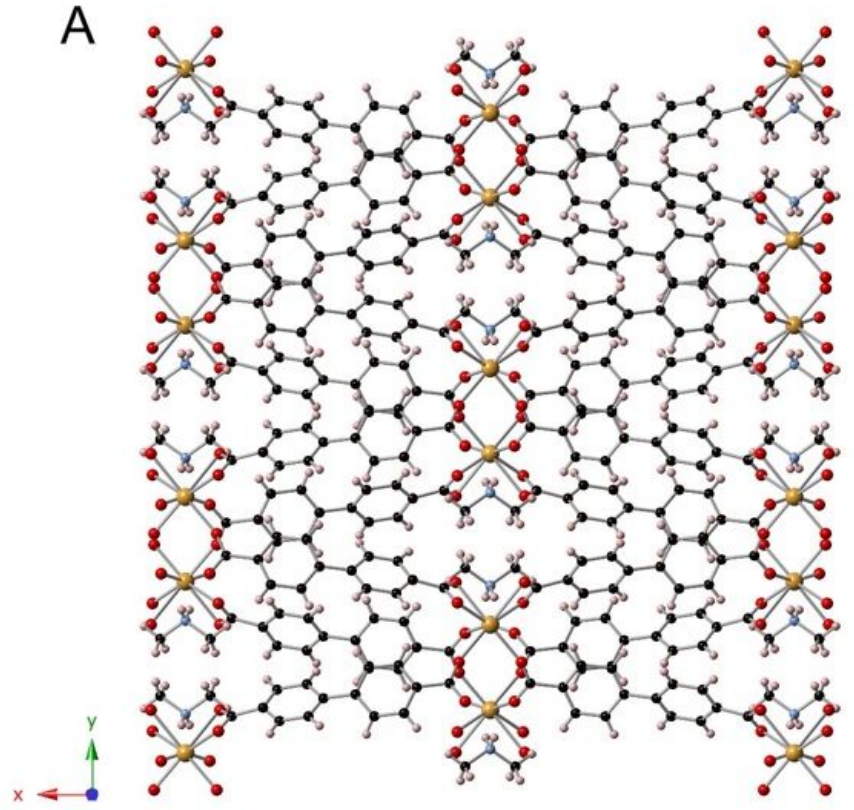

C
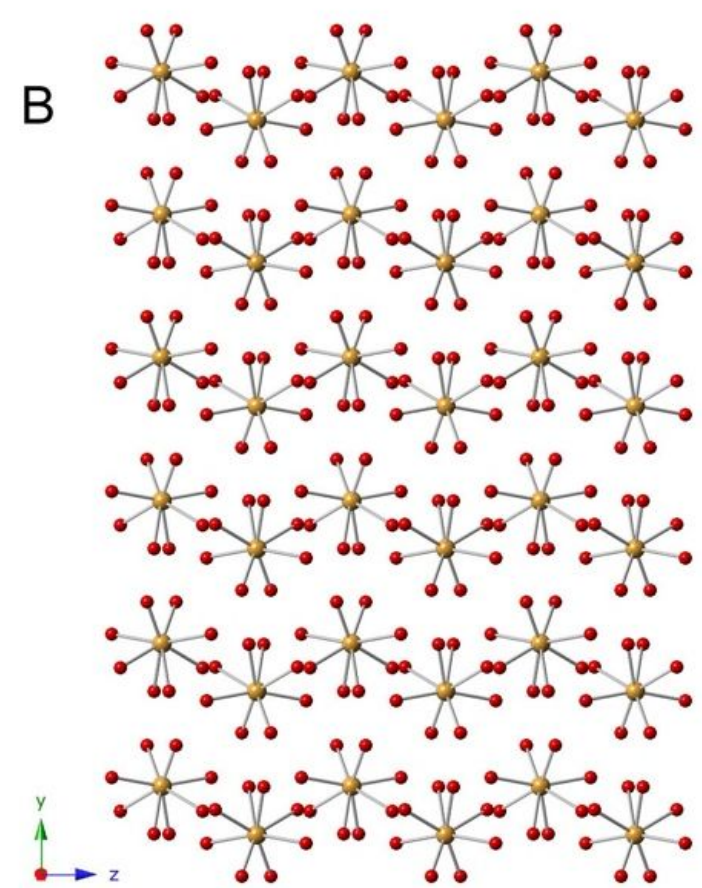

Eu1

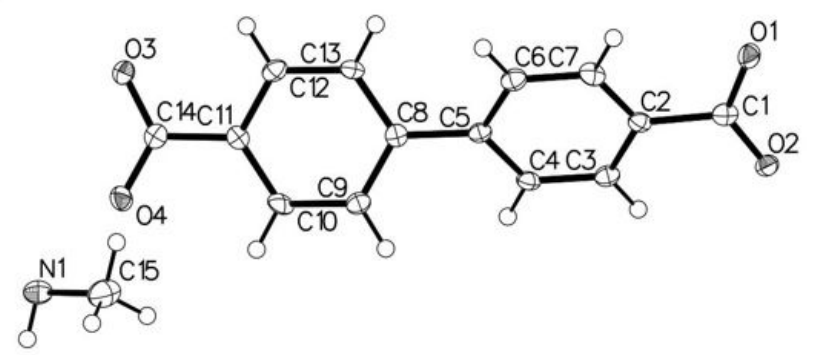

Figure S3. Crystallographic projections of SLUG-46 (Eu): A) View along the $c$-axis, showing the metal centers surrounded by bpdc ${ }^{2-}$ ligands and the extra-framework charge-balancing dimethylammonium ions close to the metal centers $(\mathrm{Eu}$ - orange; $\mathrm{O}$ - red; $\mathrm{C}$ - black; $\mathrm{N}$ - light blue; $\mathrm{H}$ - pink); B) View along the $a$-axis of one layer of isolated $\mathrm{EuO}_{8}$ centers $(\mathrm{C}, \mathrm{N}$ and $\mathrm{H}$ omitted for clarity); C) ORTEP (Oak Ridge thermal ellipsoid plot) diagram of SLUG-46 and atomic numbering scheme. Thermal ellipsoids are calculated at $50 \%$ probability. 

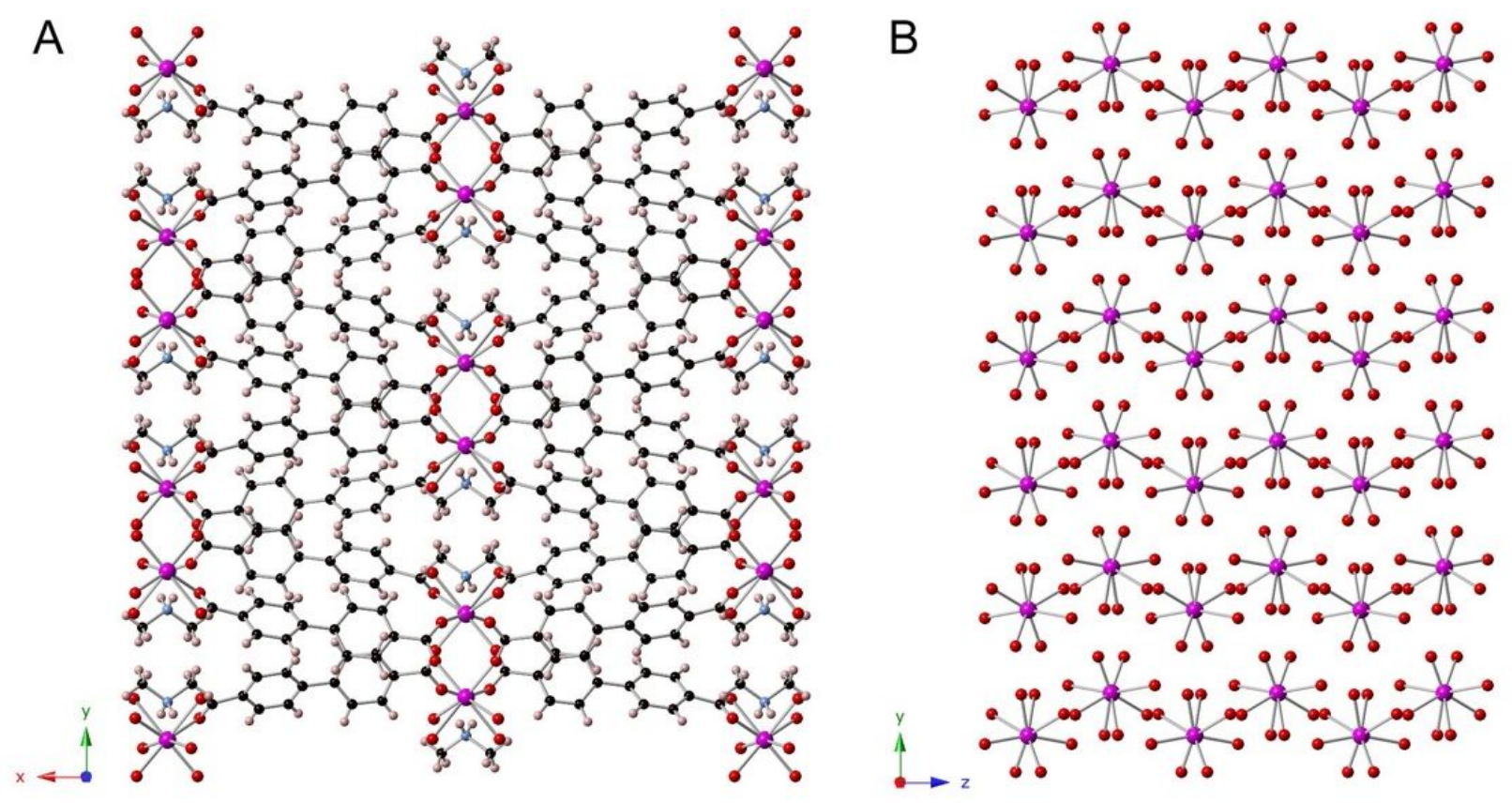

C

Gd1

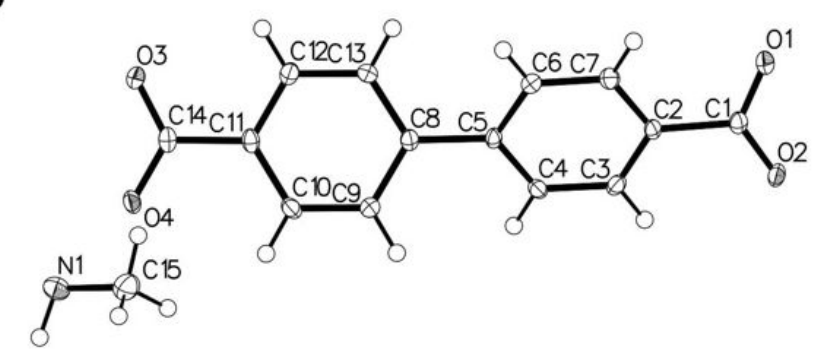

Figure S4. Crystallographic projections of SLUG-47 (Gd): A) View along the $c$-axis, showing the metal centers surrounded by bpdc ${ }^{2-}$ ligands and the extra-framework charge-balancing dimethylammonium ions close to the metal centers ( $\mathrm{Gd}$ - purple; $\mathrm{O}$ - red; $\mathrm{C}$ - black; $\mathrm{N}$ - light blue; $\mathrm{H}$ - pink); B) View along the $a$-axis of one layer of isolated $\mathrm{GdO}_{8}$ centers $(\mathrm{C}, \mathrm{N}$ and $\mathrm{H}$ omitted for clarity); C) ORTEP (Oak Ridge thermal ellipsoid plot) diagram of SLUG-47 and atomic numbering scheme. Thermal ellipsoids are calculated at $50 \%$ probability. 

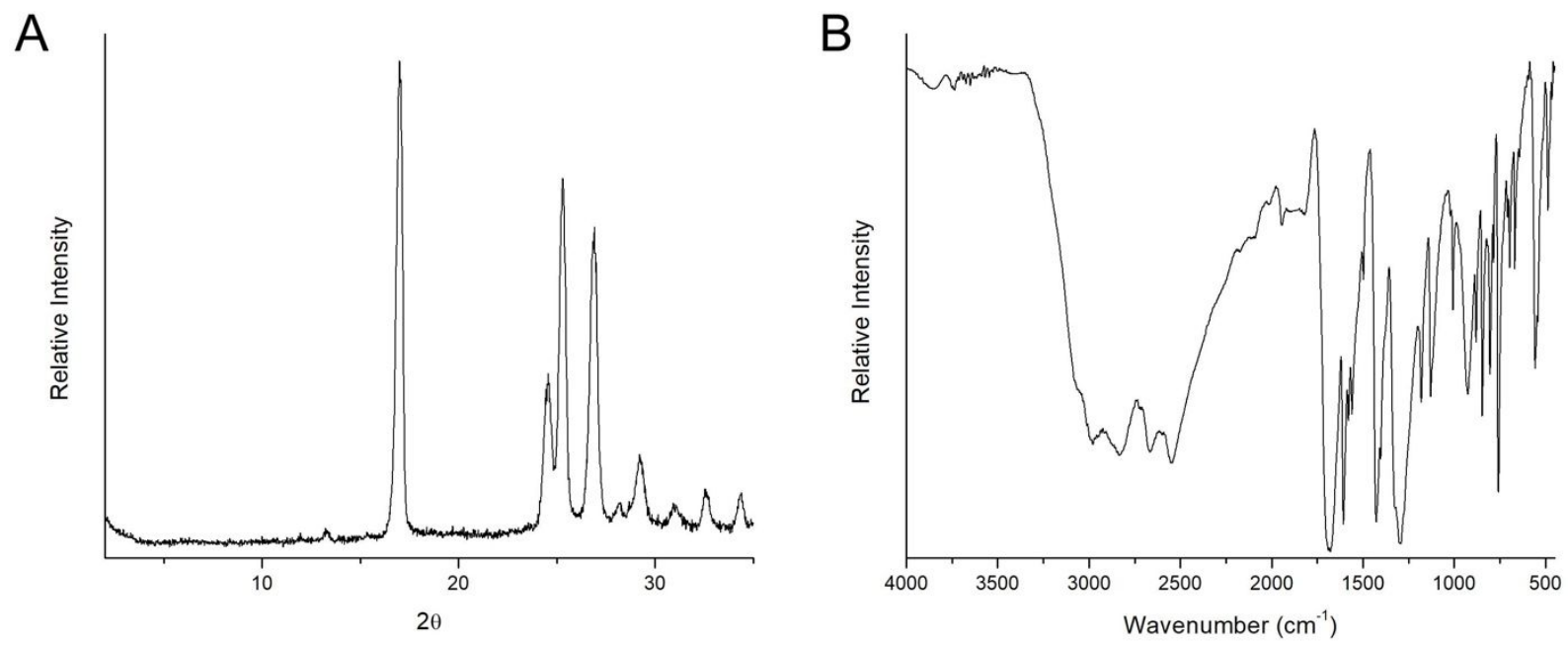

Figure S5. Characterizations of the free ligand $\mathrm{H}_{2}$ bpdc: A) PXRD pattern; B) FTIR spectrum.

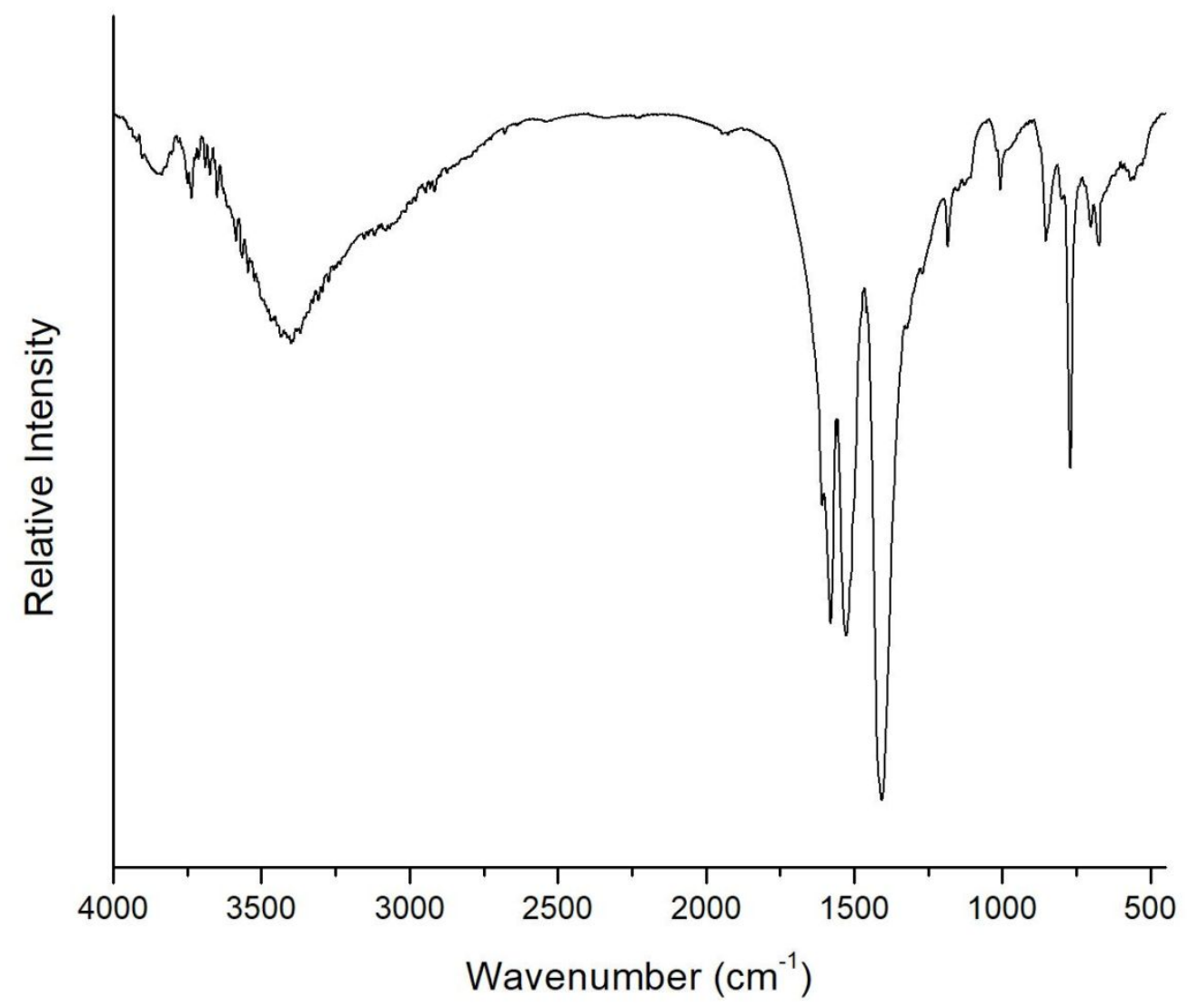

Figure S6. FTIR spectrum of the intermediate structure after heating SLUG-46 (Eu) to $375{ }^{\circ} \mathrm{C}$. 
Figure S7. Optical image of SLUG-46 (Eu) and post-heating samples, illuminated under $254 \mathrm{~nm}$ light. The photoluminescence is quenched after heating to $375^{\circ} \mathrm{C}$, signifying a disruption of the LMCT process.
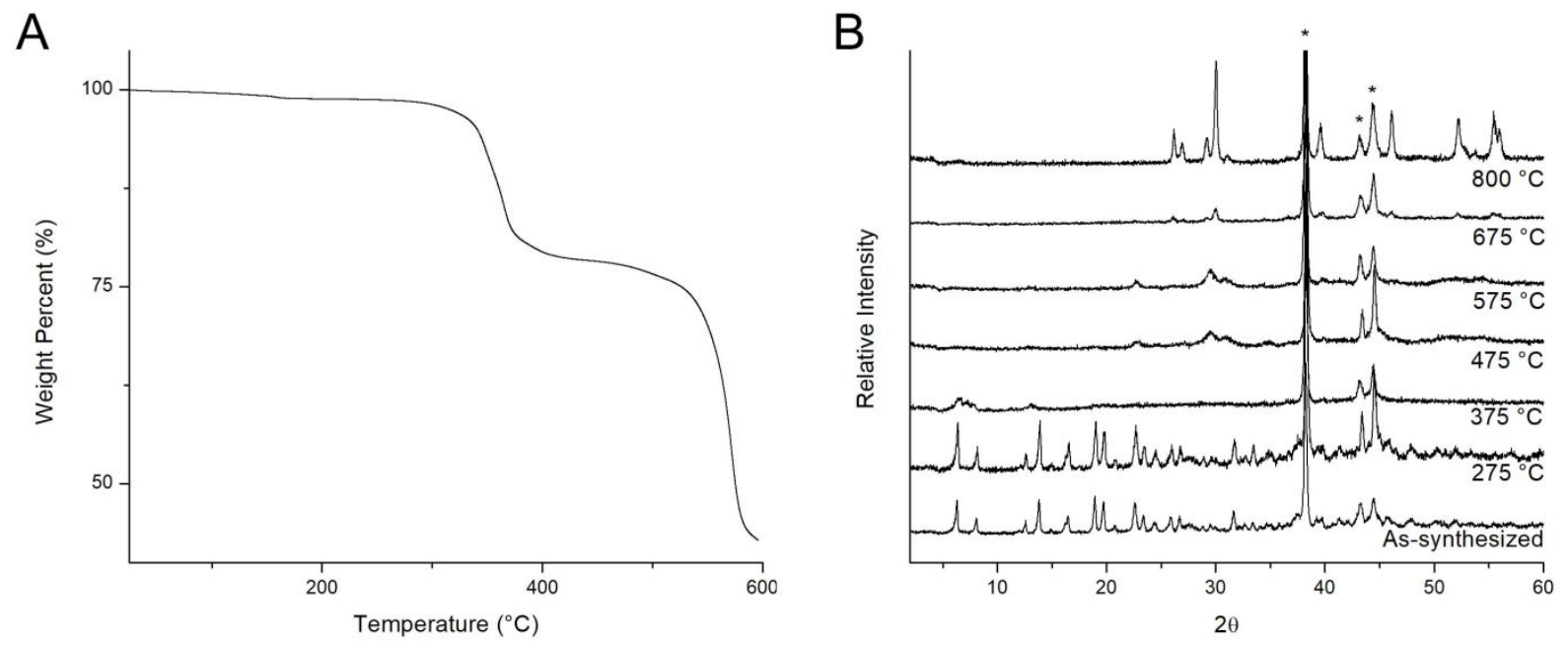

Figure S8. A) Thermogravimetric trace of SLUG-43 (La); B) Ex situ VT-PXRD of SLUG-43 (La), with asterisks denoting peaks due to the aluminum sample holder. 

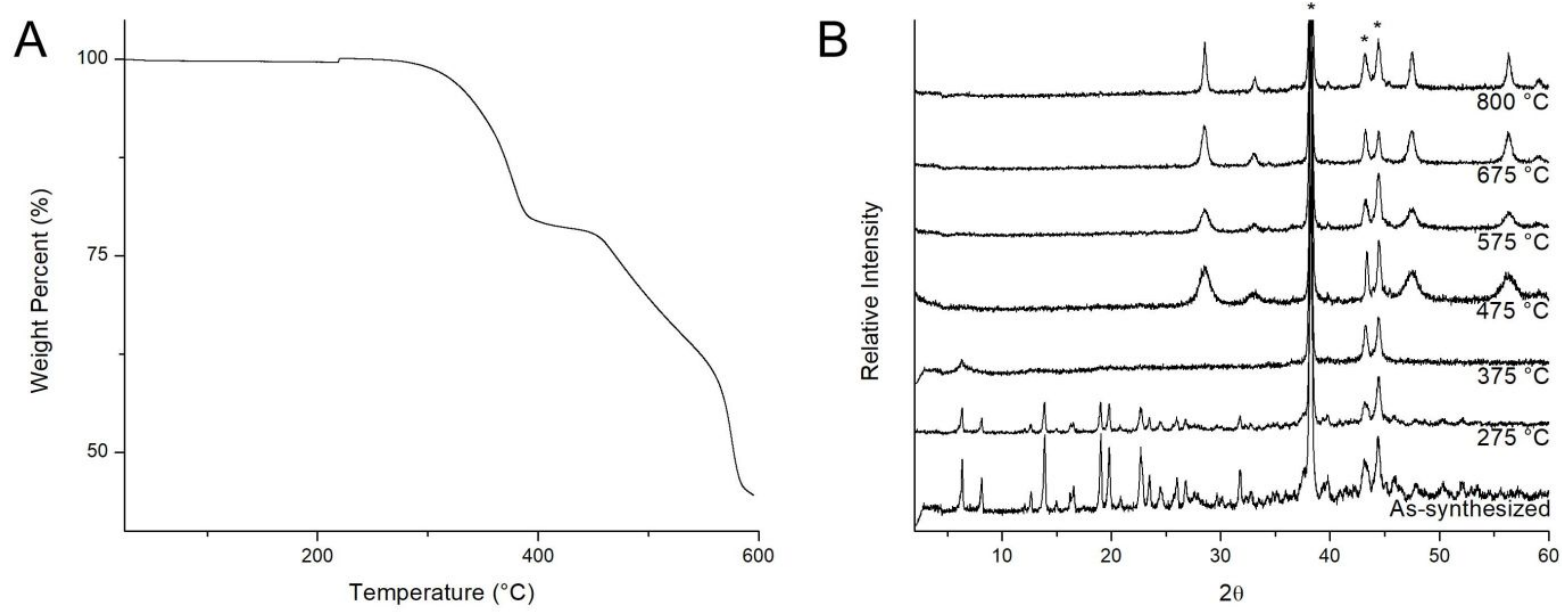

Figure S9. A) Thermogravimetric trace of SLUG-44 (Ce); B) Ex situ VT-PXRD of SLUG-44 (Ce), with asterisks denoting peaks due to the aluminum sample holder.
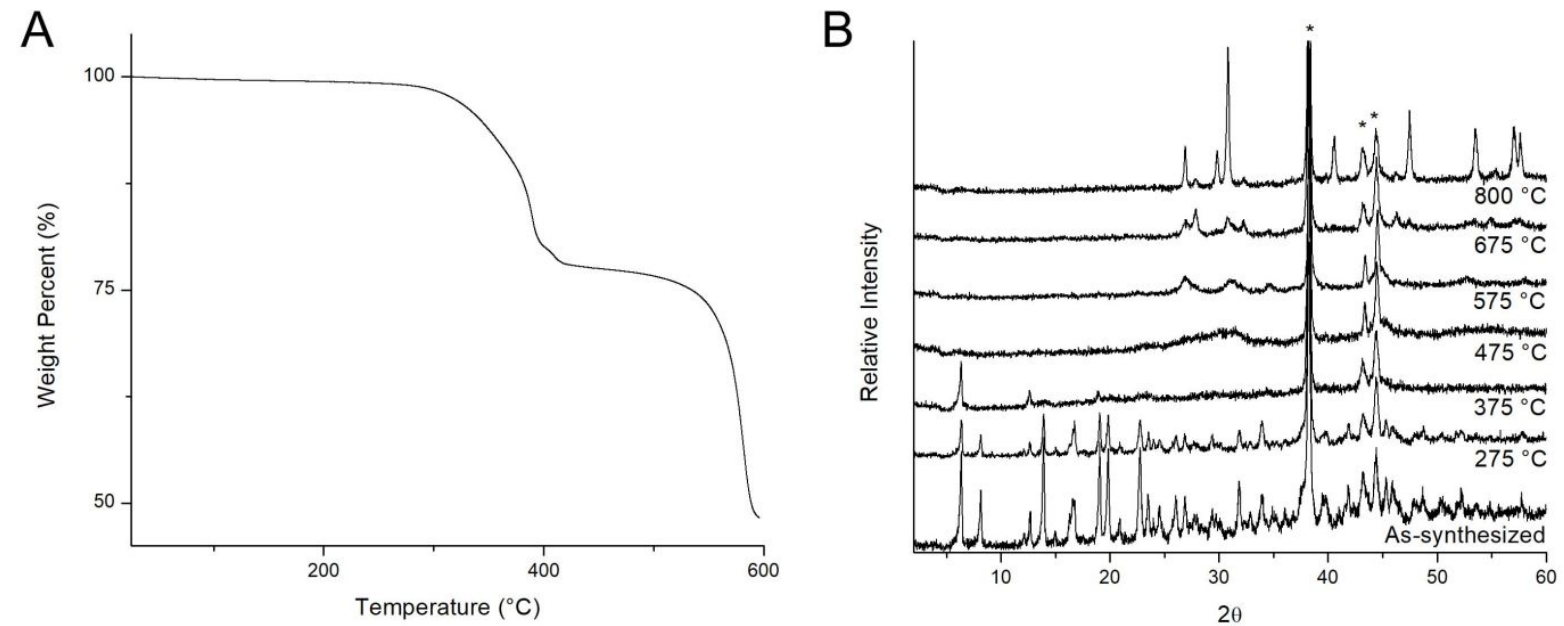

Figure S10. A) Thermogravimetric trace of SLUG-45 (Nd); B) Ex situ VT-PXRD of SLUG-45 (Nd), with asterisks denoting peaks due to the aluminum sample holder. 

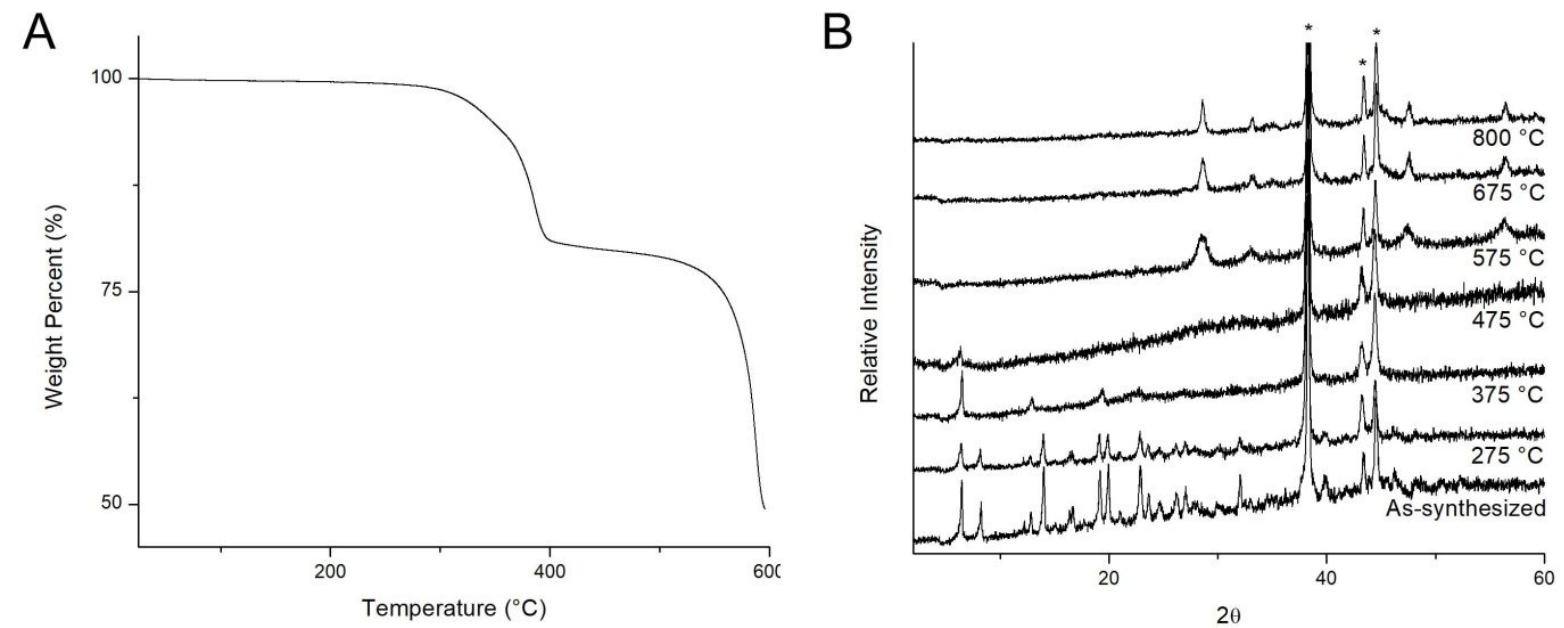

Figure S11. A) Thermogravimetric trace of SLUG-47 (Gd); B) Ex situ VT-PXRD of SLUG-47 (Gd), with asterisks denoting peaks due to the aluminum sample holder.
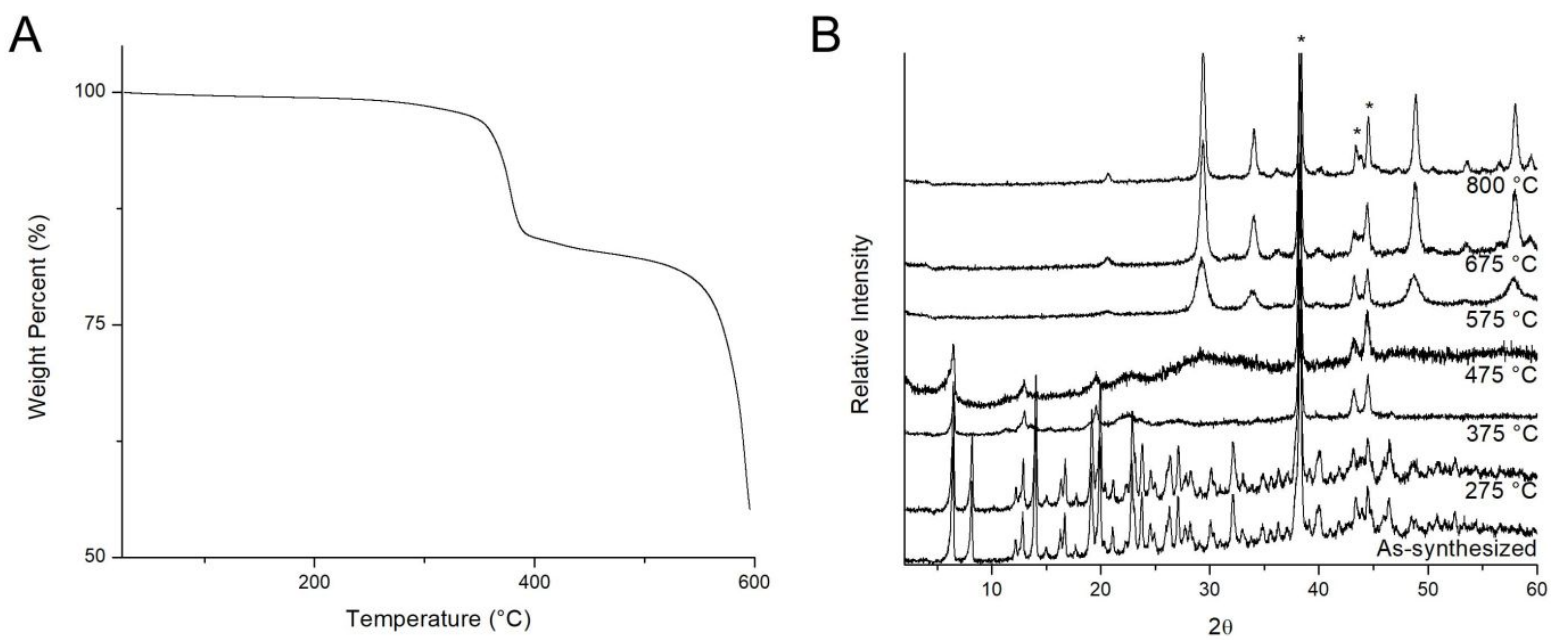

Figure S12. A) Thermogravimetric trace of SLUG-48 (Er); B) Ex situ VT-PXRD of SLUG-48 (Er), with asterisks denoting peaks due to the aluminum sample holder. 


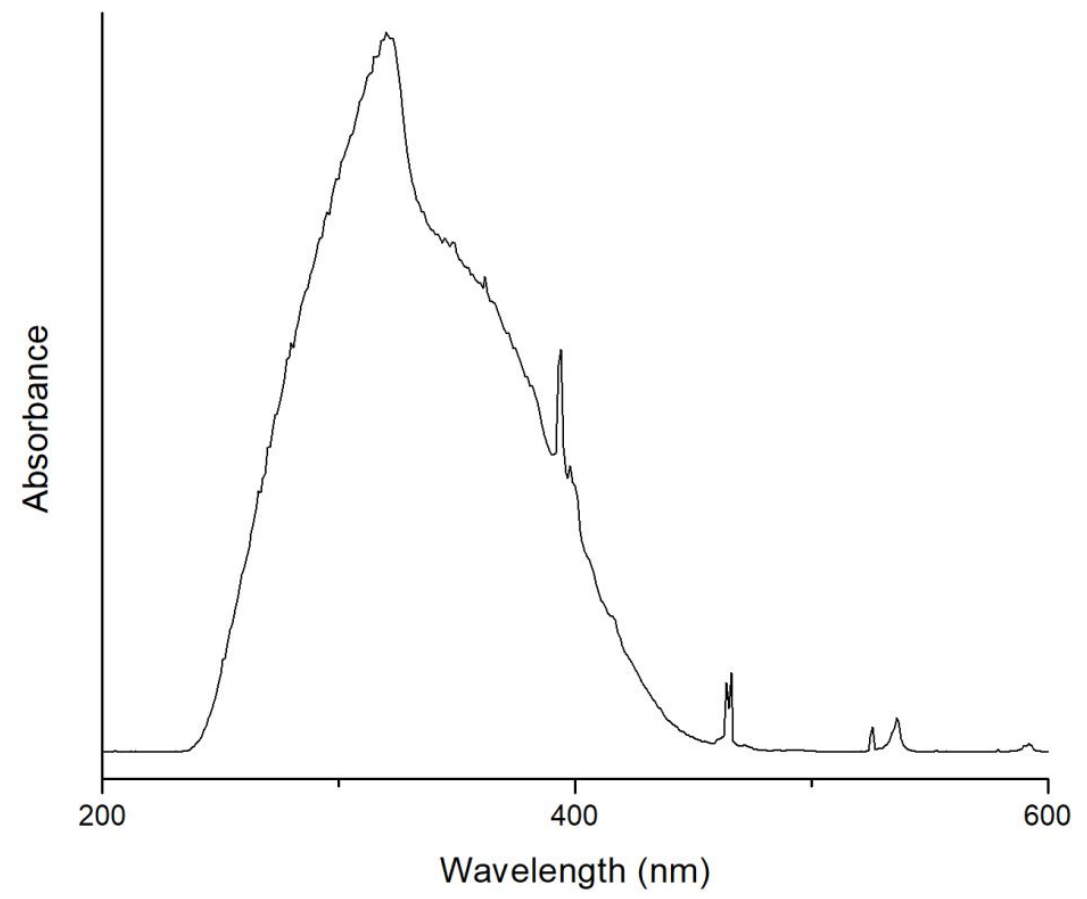

Figure S13. Solid state excitation spectrum of SLUG-46 (Eu). 